\title{
Effects of an iron-based fuel-borne catalyst and a diesel particle filter on exhaust toxicity in lung cells in vitro
}

\author{
Sandro Steiner • Jan Czerwinski • Pierre Comte • \\ Norbert V. Heeb • Andreas Mayer • Alke Petri-Fink • \\ Barbara Rothen-Rutishauser
}

Received: 14 January 2014 /Revised: 28 April 2014 / Accepted: 6 May 2014 / Published online: 1 June 2014

(C) Springer-Verlag Berlin Heidelberg 2014

\begin{abstract}
Metal-containing fuel additives catalyzing soot combustion in diesel particle filters are used in a widespread manner, and with the growing popularity of diesel vehicles, their application is expected to increase in the near future. Detailed investigation into how such additives affect exhaust toxicity is therefore necessary and has to be performed before epidemiological evidence points towards adverse effects of their application. The present study investigates how the addition of an iron-based fuel additive (Satacen ${ }^{\circledR} 3,40$ ppm Fe) to low-sulfur diesel affects the in vitro cytotoxic, oxidative, (pro-)inflammatory, and mutagenic activity of the exhaust of a passenger car operated under constant, low-load conditions by exposing a three-dimensional model of the human airway epithelium to complete exhaust at the air-liquid interface.
\end{abstract}

Published in the topical collection Aerosols and Health with guest editor Ralf Zimmermann.

Electronic supplementary material The online version of this article (doi:10.1007/s00216-014-7878-5) contains supplementary material, which is available to authorized users.

S. Steiner $\cdot$ A. Petri-Fink $\cdot$ B. Rothen-Rutishauser $(\bowtie)$

Adolphe Merkle Institute, University of Fribourg, Route de

l'Ancienne Papeterie, P.O. Box 209, 1723 Fribourg, Switzerland

e-mail: barbara.rothen@unifr.ch

J. Czerwinski $\cdot$ P. Comte

Laboratory for IC-Engines and Exhaust Gas Control,

Bern University of Applied Sciences, Gwerdtstrasse 5,

CH-2560 Nidau, Switzerland

N. V. Heeb

EMPA, Swiss Federal Laboratories for Materials Testing and

Research, Uberlandstrasse 129, 8600 Dubendorf, Switzerland

A. Mayer

TTM, Technik Thermische Maschinen, Fohrholzlistrasse 14b,

5443 Niederrohrdorf, Switzerland

B. Rothen-Rutishauser

Respiratory Medicine, Bern University Hospital, Bern, Switzerland
We could show that the use of the iron catalyst without and with filter technology has positive as well as negative effects on exhaust toxicity compared to exhaust with no additives: it decreases the oxidative and, compared to a non-catalyzed diesel particle filter, the mutagenic potential of diesel exhaust, but increases (pro-)inflammatory effects. The presence of a diesel particle filter also influences the impact of Satacen ${ }^{\circledR 3}$ on exhaust toxicity, and the proper choice of the filter type to be used is of importance with regards to exhaust toxicity.

Keywords Exhaust exposures · Iron catalyst - Diesel particle filter $\cdot$ 3D lung cell model $\cdot$ Air-liquid interface

\section{Introduction}

The popularity of diesel vehicles is continuously growing. For instance, ExxonMobil estimates that between now and 2040, diesel will account for $70 \%$ of the growth in global transportation energy consumption (The outlook for energy: a view to 2040, ExxonMobil 2013). Partly, this trend can be assumed to be due to the high fuel efficiency and the robustness of diesel engines, both resulting in considerable economic advantages over gasoline-fueled engines.

Together with the high fuel efficiency, however, comes the production of large numbers of exhaust particles, mostly consisting of elemental carbon and adsorbed hydrocarbons [1]. Adverse health effects caused by these diesel exhaust particles (DEPs) have been described extensively in numerous in vitro, in vivo, and epidemiological studies [2-4], and consequently, emission legislations on diesel engine emissions including DEPs became more stringent. In order to cope with these regulations, a number of exhaust aftertreatment systems have been developed, among the most common ones being diesel particle filters, and among these, the most notable ones are the wall-flow filters $[5,6]$. By forcing the exhaust stream 
through a porous ceramic matrix, DEPs can be removed from the emissions with efficiencies higher than $99 \%[6,7]$. To keep backpressures over the filter in a certain range, accumulating particles have to be combusted periodically; otherwise, fuel efficiency drops drastically, and the engine may be rendered nonfunctional [1]. This process, called filter regeneration, relies on the oxidation of the deposited soot particles, which because of the high ignition temperature required for combustion of soot (above $550^{\circ} \mathrm{C}$ ) does not take place under the normal operation temperature of the filter $[1,8]$. Several solutions to this problem have been developed, one being the use of catalytically active fuel additives, so-called fuel-borne catalysts (FBCs) [1, 8-10]. FBCs are usually dispersions of metal-organic compounds or metal oxides that are added in low doses to the fuel. During combustion, these catalysts are transformed to nanometer-sized metal oxide particles incorporated into the soot particles, providing high contact area between substrate and catalyst and thereby efficiently lowering the soot ignition temperature by $250-300{ }^{\circ} \mathrm{C}[9,11]$.

FBCs not only assist filter regeneration but can have profound effects on the combustion process itself, e.g., by decreasing soot formation by assuring a more complete combustion [12-14]. Obviously, not only soot formation, but the whole exhaust composition will be affected by the presence of a catalyst in the combustion chamber; hence, once an additive is used by a given engine, a new exhaust type is formed. Besides its technical performance, the complete investigation of an additive's quality therefore includes the assessment of its effects on exhaust toxicity. Satacen ${ }^{\circledR 3}$ (Innospec Inc.) is an iron-based fuel additive containing a ferrocene-like iron complex as an active substance which is diesel fuel soluble. It is commercially available, and its effects on exhaust composition including genotoxic compounds have been described before [15-17]. Only few studies discuss how iron-based FBCs affect exhaust toxicity in vitro or in vivo, however [18-20].

Shi and coworkers [18] report that a non-catalyzed diesel particle filter (DPF) in combination with Satacen ${ }^{\circledR} 3$, even though efficiently reducing the emitted mass of DEPs, does not reduce exhaust mutagenicity in Ames test experiments using Salmonella typhimurium. Wenger and coworkers [19-20] showed in in vitro cell assays that iron-based FBCs in combination with DPFs lowered emissions of agonists of the human aryl hydrocarbon receptor and the estrogen receptor.

In the present study, we performed a detailed investigation on how Satacen ${ }^{\circledR 3}$ affects exhaust toxicity in terms of cytotoxicity, oxidative stress, (pro-)inflammation, and mutagenicity. Exhausts produced from both, Satacen ${ }^{\circledR} 3$-additized and non-additized fuels were tested with and without DPF (It has to be mentioned here that according to Swiss regulations, fuel additives such as Satacen ${ }^{\circledR} 3$ are not allowed to be used without efficient DPF). Except for the mutagenicity testing, the results obtained for filtered exhaust produced from nonadditized fuel have been published elsewhere [21]. For mutagenicity assessment, we used a variation of the Ames test, and for all other endpoints a sophisticated triple cell coculture model of the human respiratory barrier. This model contains the two most important types of lung-resident immune cells (macrophages and dendritic cells) and is able to reproduce a basic set of immunological functions [22]. All exposure experiments were performed using complete and freshly produced exhaust, which is why artifacts originating from exhaust aging or biased sample generation can be ruled out. The cell cultures were exposed at the air-liquid interface, which further reduces experimental bias by eliminating interactions between the test exhaust and cell culture medium to a minimum.

\section{Materials and methods}

\section{Exhaust production}

The test vehicle was a diesel passenger car, with direct injection, an empty load of $1,350 \mathrm{~kg}$, engine displacement of $1,998 \mathrm{~cm}^{3}, 60 \mathrm{~kW}$ at 4,300 rpm, model year of 1998, and mileage in course of the experiments at 70,000-80,000 km.

Four different exhaust types were tested for their toxicity: (i) exhaust produced from reference fuel (REF), a commercial low-sulfur fossil diesel, according to the European standard SN-EN 590, with no exhaust aftertreatment installed; (ii) filtered exhaust, produced from the same fuel, but filtered by a non-catalyzed wall-flow DPF (DPF); (iii) exhaust produced from reference fuel + Satacen ${ }^{\circledR 3}$ at an iron content of $40 \mathrm{ppm}$ without exhaust aftertreatment (SATACEN); and (iv) exhaust produced from reference fuel + Satacen ${ }^{\circledR} 3$ with 40 ppm iron, filtered by a non-catalyzed wall-flow DPF (SATACEN+DPF). The filter type was IBIDEN, with $200 \mathrm{cpsi}$, pore size of $10 \mu \mathrm{m}$ with a narrow pore-size distribution, as used in a Peugeot 406. The oxidative catalyst had been removed. The filter was installed at the tailpipe of the test vehicle, and active regeneration was not initiated during the exposure experiments. Before exposure experiments, the filter was regenerated and loaded until the particle number emissions and the size distribution downstream the filter were stable.

\section{Cell cultures}

A 3D triple-cell coculture model of the human epithelial airway barrier as described in detail in [22] was used for assessment of exhaust effects other than mutagenicity. Briefly, a confluent layer of $16 \mathrm{HBE} 14 \mathrm{o}^{-}$epithelial cells was grown on an insert membrane. Differentiated human blood monocytederived macrophages were added on the apical side and human whole blood monocyte-derived dendritic cells on 
the basal side. Human blood monocytes were isolated from buffy coats provided by the blood donation service SRK Bern as described [22], the only adaption was the use of CD14 MicroBeads (Miltenyi Biotec) for monocyte isolation, which significantly increases the purity of the isolated cells.

\section{Exposure system}

The exhaust exposure system has previously been used for cell exposure experiments and is described in detail elsewhere [21, 23-25]. The system provides two exposure chambers both of which are kept at identical conditions $\left(37^{\circ} \mathrm{C}, 5 \%\right.$ $\mathrm{CO}_{2}, 85 \%$ relative humidity). One chamber is used for the treatment of negative controls with cell cultures exposed to filtered air, and the other is used for exhaust exposure. Exhaust samples were collected directly at the tailpipe of the test vehicle, diluted 10 -fold with filtered air and through rubber tubings of $3 \mathrm{~m}$ in length (a delay of less than $30 \mathrm{~s}$ ) brought to the exposure chamber (with a volume of 41 ) at a constant volume flow of $2 \mathrm{l} / \mathrm{min}$. A schematic view of the exposure setup is shown in Fig. 1.

\section{Exhaust characterization}

The exposure experiments were performed at the exhaust gas control station of the Bern University of Applied Sciences in Nidau, Switzerland, an institution officially accredited for exhaust gas analysis and control by the Swiss government. Exhaust samples were characterized in parallel to the exposure experiments, using a part of the exhaust samples that were used for exposure. The particle size-number distribution was measured in the 10-fold diluted exhaust using a scanning mobility particle sizer (differential mobility analyzer, TSI 3081; condensation particle counter, TSI $3772 \mathrm{~A}$ ), and the concentrations of carbon monoxide (CO), total volatile hydrocarbons (HC), nitrogen oxides $\left(\mathrm{NO}_{x}\right)$, and nitric oxide (NO) were measured using the Horiba MEXA-9400H exhaust gas measuring system. Concentrations of nitrogen dioxide $\left(\mathrm{NO}_{2}\right)$ were estimated based on the assumption that $\mathrm{NO}_{x}$ consists of $\mathrm{NO}$ and $\mathrm{NO}_{2}$ only.

\section{Exposure conditions}

The cell cultures were exposed at the air-liquid interface, in six-well cell culture insert with no cell culture medium on the apical side and $1.2 \mathrm{ml}$ cell culture medium in the lower compartment as described by Muller et al. [24], for 2 or $6 \mathrm{~h}$ in order to reflect a low- and a high-dose exposure. All samples were then post-incubated for $6 \mathrm{~h}$ at $37{ }^{\circ} \mathrm{C}, 5 \%$ $\mathrm{CO}_{2}$, and $80 \%$ relative humidity. On each sampling day, identical cell cultures were exposed to diluted diesel exhaust or to filtered ambient air for control. To test for the quality and health of the cell cultures, untreated controls were kept at the air-liquid interface in the incubator.

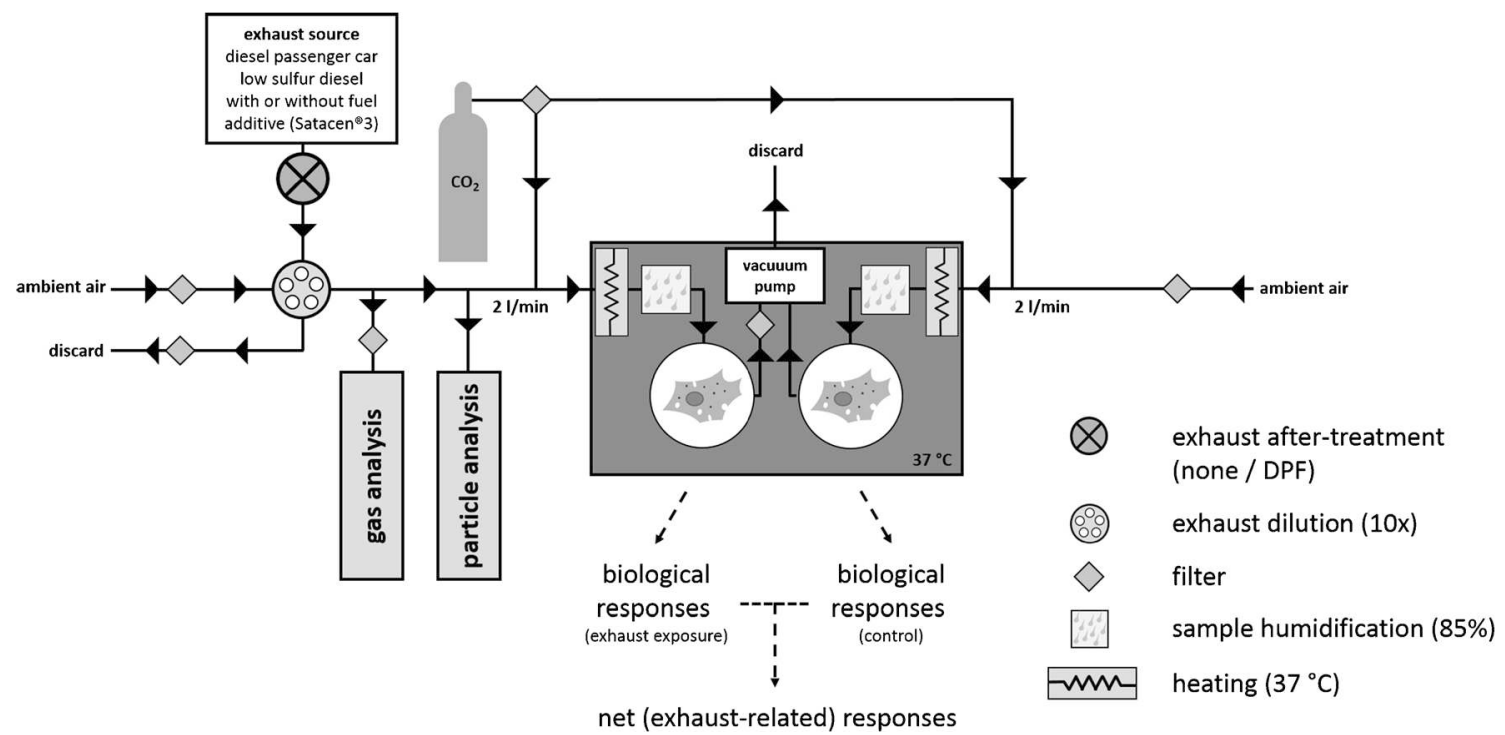

Fig. 1 Schematic view of the experimental setup. Test exhaust is produced by a test engine (in this case, a diesel passenger car) that can be operated under the desired conditions with or without the exhaust aftertreatment of choice. Samples of the freshly produced exhaust are diluted with filtered ambient air and after addition of $\mathrm{CO}_{2}(5 \%)$, humidification $\left(85 \%\right.$ relative humidity), and heating $\left(37^{\circ} \mathrm{C}\right)$, directly used for cell exposures. In parallel to the exhaust exposure, an identical set of cell cultures is exposes to filtered air under otherwise identical conditions. Comparing the biological responses to exhaust exposures to the biological responses to air exposures allows eliminating any non-exhaust-related effects. A more detailed description of the exposure system and the experimental procedure and examples for its application can be found in $[21,23-28]$ 
Laser scanning microscopy

Cell cultures were fixed with paraformaldehyde $(3 \%$ in phosphate-buffered saline $\mathrm{pH}$ 7.4). After permeabilization with $0.2 \%$ Triton $\mathrm{X}-100$, the samples were stained with phalloidin rhodamine to label the F-actin cytoskeleton and with 4',6'-diamidino-2-phenylindole (DAPI) to label the cell nuclei as previously described [24] and subsequently imaged by laser scanning microscopy.

\section{Cytotoxicity}

The release of the cytosolic protein lactate dehydrogenase (LDH) into the culture medium was used to estimate cell membrane integrity and hence cytotoxicity of the exhaust. The total amount of extracellular LDH was quantified using an LDH detection kit (Cytotoxicity Detection Kit, Roche).

\section{Oxidative stress}

The level of oxidative stress induced by exhaust exposure was estimated by quantification of reduced glutathione (GSH) in the cell cultures using a glutathione assay kit (Cayman Chemical). Detected concentrations of reduced GSH are reported relative to the total protein concentrations in the samples, which were quantified using the Pierce BCA Protein Assay kit (Pierce).

\section{(Pro-)inflammatory reactions}

Relative expression levels of the genes tumor necrosis factor $(T N F)$ and interleukin-8 $(I L-8)$ were measured by real-time RT-PCR using the $\Delta \Delta \mathrm{C}_{\mathrm{t}}$ method with glyceraldehyde-3phosphate dehydrogenase $(G A P D H)$ as the internal standard gene as described previously [21]. The extracellular concentrations of the according gene products TNF- $\alpha$ and IL- 8 in the culture medium were quantified by enzyme-linked immunosorbent assays (ELISA) using the human TNF-alpha DuoSet and the human CXCL8/IL-8 DuoSet (R\&D Systems.

\section{Exhaust mutagenicity}

Exhaust mutagenicity was tested using the Ames MPFTM 98/ 100 mutagenicity assay kit (Microplate format) from Xenometrix (S. typhimurium, strains TA98 and TA100) in a direct exposure approach. Bacterial overnight cultures were cultivated, diluted, and split according to the manufacturer's protocol and placed into the exhaust exposure system as described for the human lung cell cultures. Exposures were performed for 2,4 , and $6 \mathrm{~h}$, followed by a 48-h period of incubation at $37{ }^{\circ} \mathrm{C}$ in indicator medium. Exposures were conducted without S9 microsomal activation since its effect was reported to be minor and does not necessarily represent the metabolic activation that occurs in lung tissue in vivo [29].

Data analysis and statistics

For each experiment, human blood-derived monocytes were isolated from a different buffy coat and, hence, from a different blood donor. Variations in the absolute values measured for the background (filtered air exposure) between different sets of cell cultures were therefore expected and observed. Consequentially, all data are presented normalized to the filtered air exposure with the response of the filtered air exposure being equal to 1 . Absolute values are reported in the Electronic Supplementary Material Table S2.

For the Ames test results, no statistical evaluation was performed, but the commonly accepted rule that a 3-fold or higher increase in the number of revertants (compared to the untreated control) indicates mutagenicity of the test substance was applied.

Statistical evaluation of the results obtained with human lung cell cultures was performed by the $t$ test prior to data normalization. Since in a single series of experiments (exposure to either filtered air, REF, REF+DPF, SATACEN, or SATACEN+DPF exhaust for 2 or $6 \mathrm{~h}$ ) identical cell cultures were used for filtered air exposure and for exhaust exposures, differences in biological responses between the treatments were considered as dependent variables, and a paired $t$ test was performed. Differences between independent variables (e.g., the responses to exposures to REF and SATACEN exhaust) were analyzed with the independent two-sample $t$ test. In both cases, $p$ values below $5 \%$ were considered statistically significant.

\section{Results and discussion}

Detailed numerical results can be retrieved in the Electronic Supplementary Material Tables S1-S3 (exhaust, cell cultures, and mutagenicity, respectively). Wherever possible, values normalized to the filtered air exposure and non-normalized values are listed there.

\section{Exhaust composition}

In the absence of the DPF, addition of Satacen ${ }^{\circledR} 3$ to the reference fuel increased the particle number emission in the diameter range between 10 and $40 \mathrm{~nm}$ significantly, whereas the number of particles with diameters around $100 \mathrm{~nm}$ was slightly decreased. The DPF removed more than $99.9 \%$ of all exhaust particles including the additional metal oxide particles originating from the FBC (Fig. 2a, b). The gaseous 

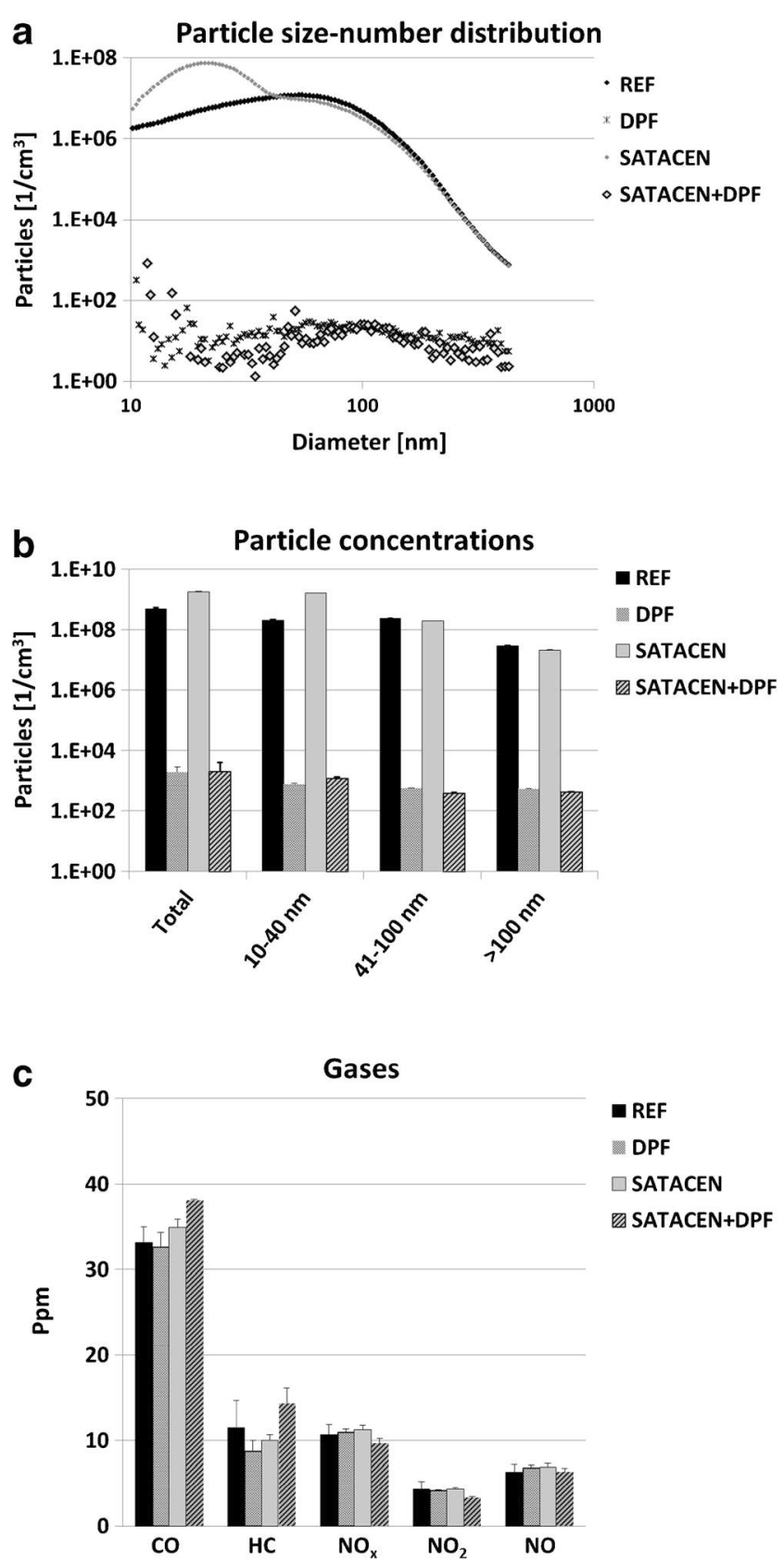

Fig. 2 Exhaust characterization. a Particle size-number distribution in the 10 -fold diluted exhausts. Prominent is the increase in the number of particles with high mobility $(10-40 \mathrm{~nm})$ in SATACEN exhaust and the virtually complete removal of particles by the DPF. b Particle concentration in the 10-fold diluted exhausts, shown as total and size-resolved. c Concentrations of gaseous exhaust components. Only marginal differences were observed. Error bars indicate standard deviations. Results for DPF exhaust were taken from a previous publication [21]

composition of the exhaust was less strongly affected at the level of resolution available in this study (Fig. 2c).

Cytotoxicity and cellular morphology

Microscopy showed no ruptures in the layer of epithelial cells. Changes in cellular morphology or signs of apoptotic stimulation such as condensed cytoplasm and pyknotic and fragmented cell nuclei were not observed, independently on the treatment (Fig. 3a). Relative to filtered air, exposure to SATACEN exhaust reduced the LDH release by $50 \%(2 \mathrm{~h})$ and $25 \%(6 \mathrm{~h})$ compared to the reference conditions (Fig. 3b). Exhaust filtration (SATACEN+DPF) also resulted in slightly less LDH release upon $2 \mathrm{~h}$ of exposure; however, an increase in extracellular LDH activity by about $50 \%$ was observed upon $6 \mathrm{~h}$ of exposure. REF exhaust had no effect, but the cytotoxicity slightly increased with DPF.

\section{Oxidative stress}

Upon REF exposure, concentrations of GSH in the reduced form were decreased to about $10 \%$ of what was measured for filtered air exposure, independently on the exposure duration (Fig. 3c). The according values for SATACEN are $43 \%(2 \mathrm{~h}$ ) and $30 \%(6 \mathrm{~h})$. Exhaust filtration additionally improved this effect: independently on the dose, SATACEN+DPF exposure resulted in about $60 \%$ of the GSH concentration measured upon filtered air exposure.

\section{(Pro-)inflammatory responses}

Induction of (pro-)inflammatory gene expression was detected for unfiltered diesel exhaust without and with SATACEN, in dependency on the exposure duration (Fig. 4a, b). Upon $2 \mathrm{~h}$ of exposure, the highest $T N F$ and $I L-8$ gene expression levels were measured for REF exhaust, and the responses to SATA CEN and SATACEN+DPF exhaust were slightly lower and comparable among each other. In contrast, upon $6 \mathrm{~h}$ of exposure, the highest activity of the genes was induced by SATA CEN exhaust. The responses to REF exhaust were comparable to those upon $2 \mathrm{~h}$ of exposure. SATACEN+DPF resulted in no $T N F$ induction, and an $I L-8$ induction comparable to the one observed for REF exhaust.

The results obtained on the protein level did not reflect gene expression levels except for the reference conditions which showed slightly increased secretion of TNF- $\alpha$ and IL8 comparable to the gene expression results (Fig. 4c, d). TNF- $\alpha$ secretion was also significantly increased by SATA CEN+DPF, but not by SATACEN exposures. SATACEN exposure for $6 \mathrm{~h}$ even decreased TNF- $\alpha$ secretion compared to filtered air. For IL-8, a similar picture was observed.

Exhaust mutagenicity

In TA100, the mutagenic potentials of unfiltered exhausts (REF and SATACEN) were virtually identical (Fig. 5a). After $6 \mathrm{~h}$ of exposure, REF and SATACEN exhaust acted mutagenic with a 3.0- and a 2.9-fold increase with a steady increase of the mutagenicity over time from 0 to $6 \mathrm{~h}$. Exhaust mutagenicity was considerably increased by the non-catalyzed DPF and 


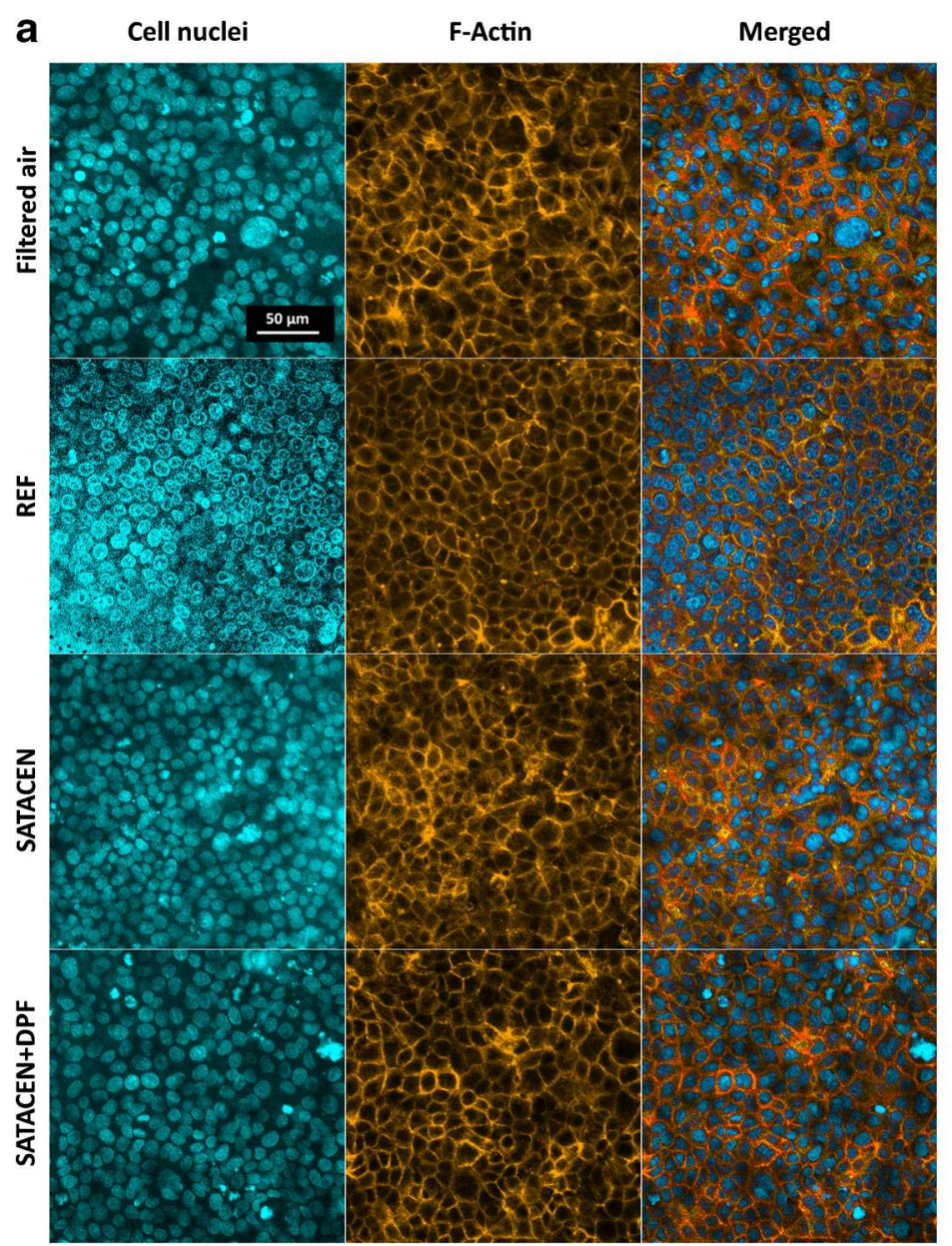

b
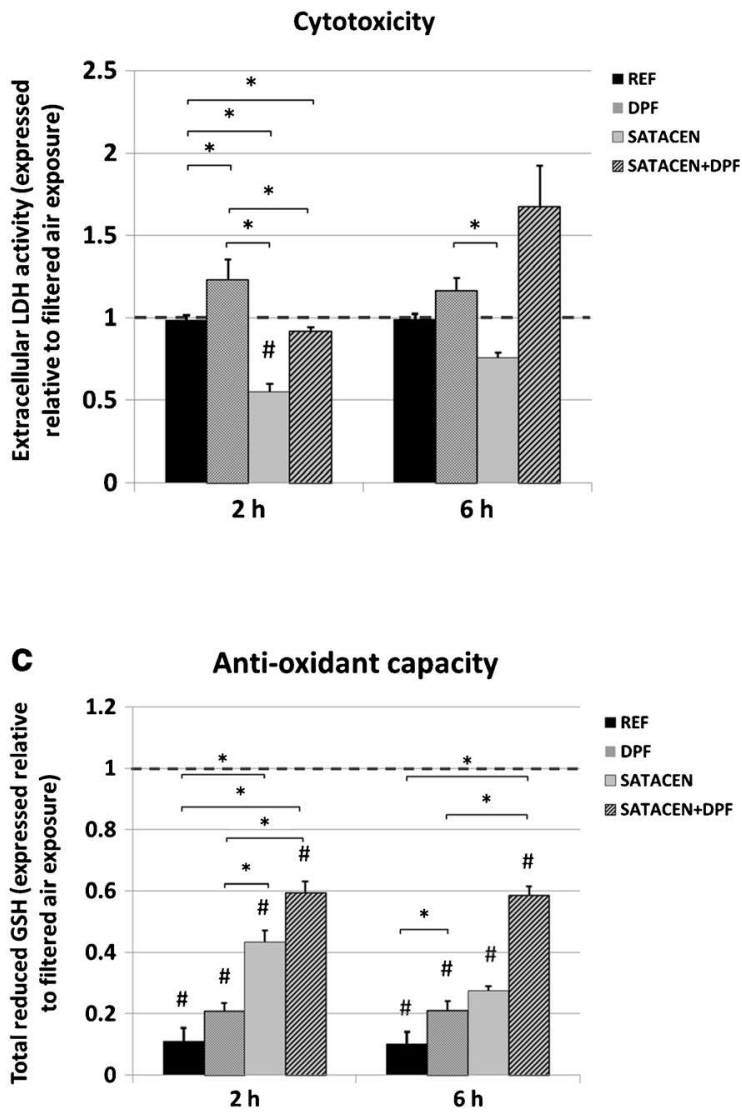

Fig. 3 Cellular morphology, cytotoxicity, and oxidative stress. a Representative laser scanning micrographs of cell cultures after exposure to filtered air or test exhausts. Only samples exposed for $6 \mathrm{~h}$ are shown. Cultures were stained for nucleic acids with DAPI and for F-actin with phalloidin rhodamin. No ruptures in the layer of epithelial cells and no changes in cellular or nuclear morphology were detected. Bar size, $50 \mu \mathrm{m}$. b Cytotoxicity, measured by quantification of extracellular $\mathrm{LDH}$, expressed normalized to filtered air exposure (equals 1 , dashed line). The decrease in LDH activity observed for SATACEN exhaust is

completely abolished by SATACEN+DPF. In TA98, only SATACEN+DPF acted mutagenic, and mutagenicity was weaker than the one observed for the DPF in TA100 (Fig. 5b).

Assessment of the toxicological responses

Considering the emissions of gaseous compounds, relatively small effects were observed under the given conditions. However, effects on the particle emissions were substantial. The application of the DPF lowered particle number emissions by more than 3 orders of magnitude. Thus, the observed toxicological responses after such an efficient filtration are most probably related to those volatile exhaust constituents that could penetrate the filter or to those that have formed in the filter during soot combustion (secondary pollutants), or the likely to be due to interferences of the large amount of $\mathrm{Fe}_{2} \mathrm{O}_{3}$ particles with the assay. $\mathbf{c}$ Cellular antioxidant capacity, measured by quantification of total reduced GSH, expressed normalized to filtered air exposure (equals 1 , dashed line). Satacen ${ }^{\mathbb{R} 3}$ decreased the oxidative potential of the exhaust, and the DPF further increased this effect. $\# p<0.05$, indicating significance between dependent samples (i.e., between filtered air and exhaust exposure); ${ }^{*} p<0.05$, indicating significance between independent samples. Error bars represent standard errors of the mean. Results for DPF exhaust were taken from a previous publication [21]

effects are related to the absence of compounds that have been removed by the filters.

As expected [7], an increase in the number of particles with diameters in the range of up to about $40 \mathrm{~nm}$ was clearly detected in the SATACEN exhaust. These particles mainly originate from nucleation of the additive $[14,30]$ and can be assumed to consist mainly of $\mathrm{Fe}_{2} \mathrm{O}_{3}$. The reduction in the concentration of larger (carbonaceous) particles brought by the FBC Satacen ${ }^{\circledR 3}$ was smaller than expected [14], which might be a consequence of different engine operation modes. Considering the biological responses to the exhaust exposures, it is important to mention that except for SATACEN+ DPF (upon $6 \mathrm{~h}$ of exposure), none of the exhausts resulted in considerable increases of extracellular LDH, and hence, no induction of (severe) cytotoxicity took place. Relative to filtered air, a 1.7-fold increase of the LDH release was observed 

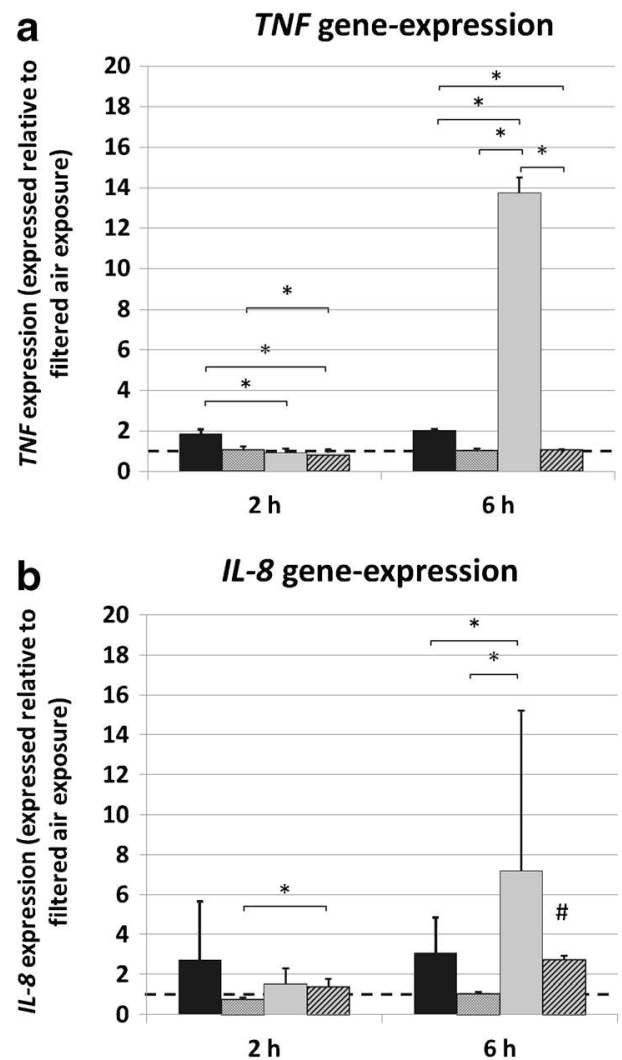

Fig. 4 (Pro-)inflammatory stimulation, measured by real-time RT-PCR on the genes $T N F$ and $I L-8(\mathbf{a}, \mathbf{b})$ and quantification of their gene products TNF- $\alpha$ and IL- 8 by ELISA (c, $\mathbf{d})$. All results are normalized to the filtered air exposures (equal 1, dashed lines). Apparent is that gene expression and protein data are not congruent, particularly upon $6 \mathrm{~h}$ of exposure to SATACEN exhaust. Likely causes are interferences of the deposited

upon $6 \mathrm{~h}$ of exposure to SATACEN+DPF exhaust. This might be interpreted as indicative for cytotoxicity, compared to the 9-fold increase measured for the positive control (treated with $0.25 \%$ triton X-100, data not shown), severe necrosis cannot be assumed, however. Also, no apparent changes of cellular morphology such as membrane rupture, condensed cytosol, or pyknotic and fragmented nuclei were observed by microscopy, which further indicates no severe cell death.

The application of the DPF alone resulted in GSH levels between REF and SATACEN, indicating that the mere removal of particles from the exhaust has little effect on its oxidative potential. The gaseous fraction therefore appears to be of importance here, and the fact that the concentrations of $\mathrm{CO}$, $\mathrm{NO}_{x}, \mathrm{NO}_{2}, \mathrm{NO}$, and $\mathrm{HC}$ were similar in all exhausts points towards the composition of the $\mathrm{HC}$ fraction. When looking at the results for (pro-)inflammatory responses, the first thing that comes to attention is that upon $6 \mathrm{~h}$ of exposures to SATA CEN exhaust, the highest gene expression levels, but the lowest protein secretion levels, were measured for both assessed cytokines. Transcriptional activity of a gene but the absence of its gene product can, in general, be explained by the time lag that has to be expected between gene transcription
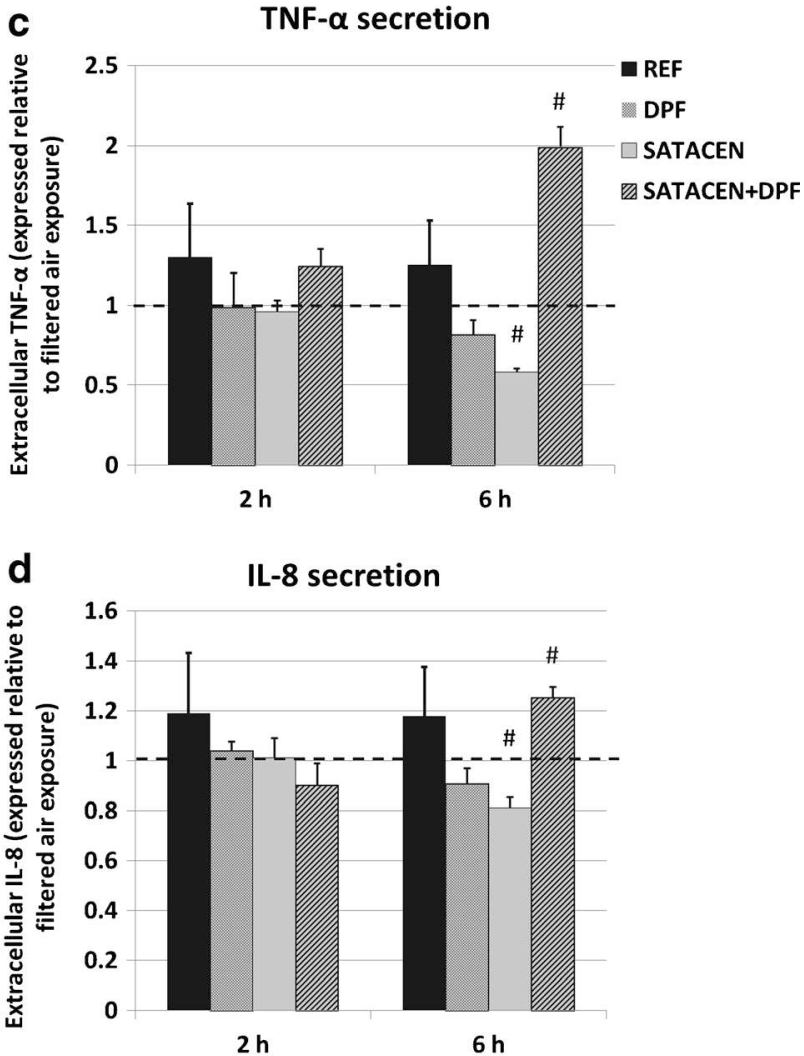

particles with the ELISA assay or posttranscriptional regulation. $\# p<0.05$, indicating significance between dependent samples (i.e., between filtered air and exhaust exposure); ${ }^{*} p<0.05$, indicating significance between independent samples. Error bars represent standard errors of the mean. Results for DPF exhaust were taken from a previous publication [21]

and protein synthesis and/or by posttranscriptional regulation. We cannot be sure, however, whether the absence of TNF- $\alpha$ and IL-8, despite the strongly induced gene expression upon SATACEN exposures, is a consequence of an interference of deposited iron particles with the ELISA test method or not. We therefore limit the discussion to the gene expression data for the SATACEN exhaust.

It is generally assumed that local inflammation in the lung upon aerosol inhalation is the result of oxidative stress, induced by deposited particles [31]. Considering the results for GSH oxidation and (pro-)inflammation, this correlation could only partially be observed. Two hours of exposures resulted in clearly detectable (even though not statistically significant) (pro-)inflammatory responses for REF, but not for SATACEN and not for DPF exhausts. This reflects the strongest drop in reduced GSH for REF exhaust, but not the differences between GSH levels measured for the other exhausts. Upon $6 \mathrm{~h}$ of exposure, the highest (pro-)inflammatory responses (on the protein or the gene transcription level) were induced by SATACEN and SATACEN+DPF exhaust, which does not reflect GSH levels at all. 

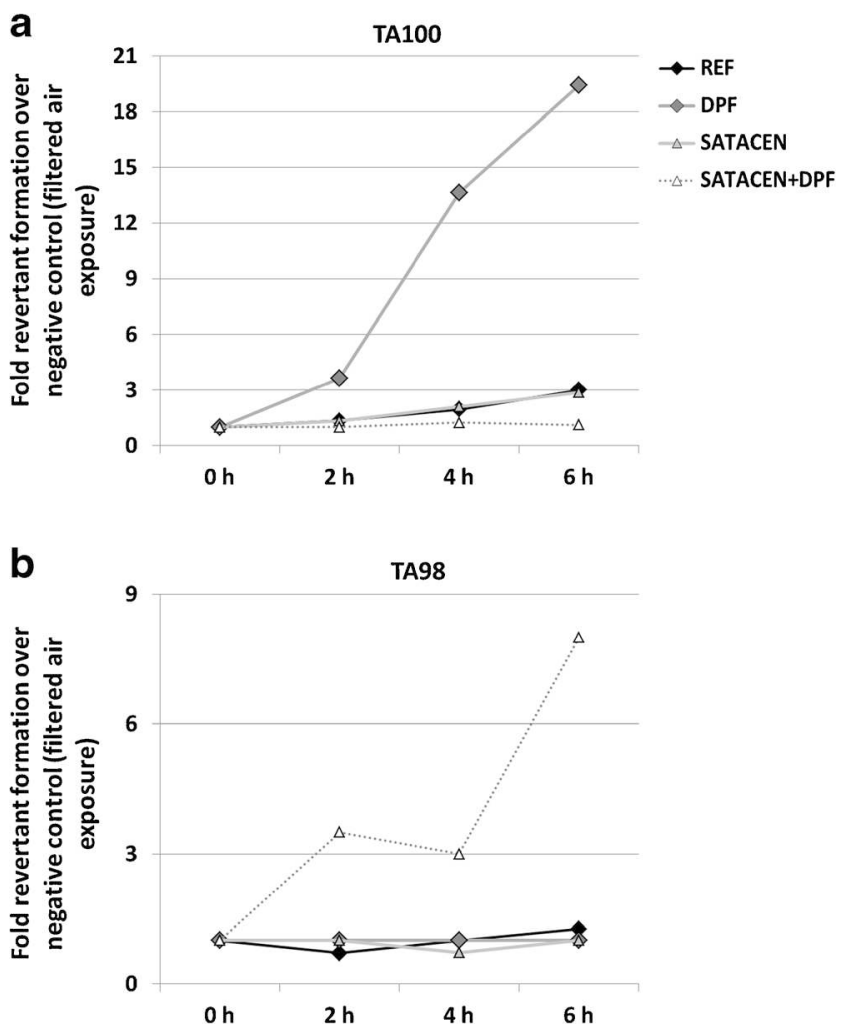

Fig. 5 Exhaust mutagenicity, measured by the bacterial Ames test (Salmonella typhimurium, strains TA100 and TA98). The fold revertant formation over the negative control is obtained by dividing the number of revertants in exposed cultures by the number of revertants in untreated cultures and indicates mutagenicity if higher or equal to 3 (indicated by the dashed line, according to Xenometrix manual). The non-catalyzed DPF increases exhaust mutagenicity in TA100, the influence of Satacen ${ }^{\circledR} 3$ varies for the two strains

Zhang and coworkers [32] showed that the oxidative stress potential of $\mathrm{Fe}_{2} \mathrm{O}_{3}$ is relatively low compared to other metal oxides and that the oxidative stress potential and (pro-)inflammatory stimulation generally correlate well for metal oxides. Our observation of SATACEN exhaust being of relatively low oxidative potential is in line with this, but not the observed high (pro-)inflammatory response upon $6 \mathrm{~h}$ of exposure. Other oxidative stress- and particle-independent factors appear to be of importance here. It has been reported that, for instance, $I L-8$ gene expression can be upregulated directly by hydrocarbons via interaction with the aryl hydrocarbon receptor, and that this upregulation is highly sensitive on the type of hydrocarbons involved, but independent on oxidative stress [33].

We therefore postulate that Satacen ${ }^{\circledR} 3$ in the absence of a filter may result in the formation of modified hydrocarbons with (pro-)inflammatory properties. This hypothesis is supported by the results obtained for exhaust mutagenicity: whereas the mutagenicity of REF and SATACEN exhaust was virtually identical in strain TA100, the DPF exhaust was of drastically increased mutagenicity, and SATACEN+DPF exhaust displayed lower mutagenicity. In contrast, in strain
TA98, only SATACEN+DPF exhaust acted mutagenic, even though considerably weaker than the non-catalyzed DPF in TA100. It has been demonstrated [15-17] that DPFs function as chemical reactors, in which exhaust components may undergo substantial chemical modifications. Most noteworthy in terms of mutagenicity is the formation or elimination of nitrated polyaromatic hydrocarbons (NPAHs) and polychlorinated dibenzodioxins (PCDDs) and -furans (PCDFs) [34, 35]. According to [17], significant formation of PCDDs and PCDFs has not been expected in a solely ironcatalyzed system. Nevertheless, the formation of certain NPAHs has been observed in various DPFs, especially in filters without catalysts and with low oxidation potential catalysts, whereas catalysts with higher oxidation potentials are generally more efficient in removing NPAHs from the exhaust than in their de novo formation by nitration reactions. The combination of an uncoated DPF and Satacen ${ }^{\circledR} 3$ provides a system of low oxidation potential [16], and assuming an approximate balance between de novo formation and oxidation of NPAHs appears reasonable. In a non-catalyzed DPF, in contrast, nitrating agents present in the exhaust from the beginning (for example, $\mathrm{NO}_{2}, \mathrm{NO}_{3}$-radicals, or nitronium ions $\left(\mathrm{NO}_{2}{ }^{+}\right)$) are sufficient for the nitration of certain hydrocarbons, while the catalytic activity for their oxidative removal is not available [16]. The result will be a net formation of chemical species of increased mutagenicity. We therefore conclude that the iron-based FBC Satacen ${ }^{\circledR 3}$ alone is not sufficiently active for the efficient oxidation of mutagenic chemicals. However, the filter functions as a reactor in which catalytically active iron oxide particles accumulate over time along with soot particles and in which organic moleculesvolatile ones and the ones adsorbed to trapped soot - are partly eliminated and partly modified by oxidation. In the absence of Satacen ${ }^{\circledR} 3$, the reactor properties are different and, therefore, also the effect on (pro-)inflammatory and mutagenic exhaust properties. Satacen ${ }^{\mathbb{3} 3}$ without DPF does not provide the prolonged interaction between catalyst and exhaust components, which will again result in a different compositions of the HC fraction and, together with the large number of additive-derived particles, will result in different (pro-)inflammatory and mutagenic properties.

Clearly, more detailed exhaust analyses would be needed to confirm the possible toxicity of the $\mathrm{HC}$ fraction and its modification on DPFs in the absence or presence of a catalytic activity (and how it is influenced by other exhaust aftertreatment systems, fuel types, and fuel additives), but it is well supported by the literature. Analytical studies report how exhaust composition, particularly the concentration of known toxic exhaust components, is affected by changing the engine equipment $[15,16,36]$, and toxicological studies report how exhaust toxicity is changed by such changes [20, 21, 37].

It is difficult to find the direct link between results of analytical and toxicological studies, which requires the 
combination of chemical exhaust analyses and exhaust toxicity. This could, on one hand, help to better understand exhaust toxicity on the molecular level (i.e., what exhaust components are actually responsible for toxicity, what are synergistic/ antagonistic effects) and would allow designing more optimal catalysts, filters, fuels, etc. on the other hand. A number of studies pursuing such a combined analytical-toxicological approach have been published, for instance in [38] in combination with $[19,25,39,40]$, but in many cases, the level of (analytical and/or toxicological) resolution is not sufficient or they suffer from the inability to find clear correlations between changes in exhaust composition and exhaust toxicity. The latter is certainly a result of the complexity of biological test systems and engine emissions, but also of the facts that for the identification of common patterns, not enough such studies have been performed and that comparison between different studies is difficult because of a lack of standardization in this field of research (e.g., different biological test systems, different exposure methods, and different biological endpoints are used).

In summary, with regard to exhausts produced under the settings applied in this work, the additive Satacen ${ }^{\circledR 3}$ when used in combination with an efficient wall-flow filter has beneficial effects on exhaust toxicity by reducing the oxidative and, to a certain extent, the mutagenic exhaust potential, as well as adverse effects by increasing the (pro-)inflammatory and cytotoxic potential. The effects of the additive strongly depend on the presence or absence of a DPF, and this study therefore implies that the choice of the filter type could further enhance or diminish the beneficial effects of Satacen ${ }^{\circledR} 3$. Future studies should therefore investigate the effect of different filter types with high resolution in terms of both exhaust chemistry and exhaust toxicity.

Further, as an addendum to our recently published work on the effect of a non-catalyzed DPF [21], we can say that in the absence of any catalyst or in conditions where catalysts do not reach the temperature required for activity, inactive DPFs may increase exhaust mutagenicity and support the de novo formation of mutagenic compounds.

\begin{abstract}
Acknowledgments The authors would like to acknowledge the financial support of the Swiss Federal Office for the Environment, Erdölvereinigung EV and VSS lubes, as well as the Adolphe Merkle Foundation, and furthermore, the Bern University of Applied Sciences, the Institute of Aerosol and Sensor Technology, Northwestern Switzerland, and the University of Rouen for technical assistance. We would also like to thank Dr. Gruenert (University of California, San Francisco) for providing the $16 \mathrm{HBE} 14 \mathrm{o}$ - cell line.
\end{abstract}

Conflict of interest Andreas Mayer is the owner and general manager of "TTM Andreas Mayer," Switzerland, an emission consulting company. As all the other authors, however, he declares to have no conflicts of interest.

\section{References}

1. van Setten BAAL, Makkee M, Moulijn JA (2001) Science and technology of catalytic diesel particulate filters. Catal Rev 43(4): 489-564. doi:10.1081/Cr-120001810

2. Ghio AJ, Smith CB, Madden MC (2012) Diesel exhaust particles and airway inflammation. Curr Opin Pulm Med 18(2):144-150. doi:10. 1097/Mcp.0b013e32834f0e2a

3. Ghio AJ, Sobus JR, Pleil JD, Madden MC (2012) Controlled human exposures to diesel exhaust. Swiss Med Wkly 142. doi:10.4414/smw. 2012.13597

4. Schwarze PE, Totlandsdal AI, Lag M, Refsnes M, Holme JA, Ovrevik J (2013) Inflammation-related effects of diesel engine exhaust particles: studies on lung cells in vitro. Biomed Res Int 2013:113. doi: $10.1155 / 2013 / 685142$

5. Adler J (2005) Ceramic diesel particulate filters. Int J Appl Ceram Technol 2(6):429-439

6. Bensaid S, Marchisio DL, Russo N, Fino D (2009) Experimental investigation of soot deposition in diesel particulate filters. Catal Today 147:S295-S300. doi:10.1016/j.cattod.2009.07.039

7. Mayer A, Czerwinski J, Wichser A, Ulrich A, Kasper M, Mooney J (2010) Metal-oxide particles in combustion engine exhaust. SAE Technical Papers 2010-01-0792

8. Johnson T (2008) Diesel engine emissions and their control an overview. Platin Met Rev 52(1):23-37. doi:10.1595/ $147106708 \times 248750$

9. Setiabudi A, Chen JL, Mul G, Makkee M, Moulijn JA (2004) CeO2 catalysed soot oxidation - the role of active oxygen to accelerate the oxidation conversion. Appl Catal B Environ 51(1):9-19. doi:10. 1016/j.apcath.2004.01.005

10. Liati A, Eggenschwiler PD (2010) Characterization of particulate matter deposited in diesel particulate filters: visual and analytical approach in macro-, micro- and nano-scales. Combust Flame 157(9):1658-1670. doi:10.1016/j. combustflame.2010.02.015

11. Okuda T, Schauer JJ, Olson MR, Shafer MM, Rutter AP, Walz KA, Morschauser PA (2009) Effects of a platinum-cerium bimetallic fuel additive on the chemical composition of diesel engine exhaust particles. Energy Fuel 23:4974-4980. doi:10.1021/Ef900370v

12. Song JH, Wang JG, Boehman AL (2006) The role of fuel-borne catalyst in diesel particulate oxidation behavior. Combust Flame 146(1-2):73-84. doi:10.1016/j.combustflame.2006.03.012

13. Jung HJ, Kittelson DB, Zachariah MR (2005) The influence of a cerium additive on ultrafine diesel particle emissions and kinetics of oxidation. Combust Flame 142(3):276-288. doi:10.1016/j. combustflame.2004.11.015

14. Skillas G, Qian Z, Baltensperger U, Matter U, Burtscher H (2000) The influence of additives on the size distribution and composition of particles produced by diesel engines. Combust Sci Technol 154:259 273. doi:10.1080/00102200008947279

15. Heeb NV, Schmid P, Kohler M, Gujer E, Zennegg M, Wenger D, Wichser A, Ulrich A, Gfeller U, Honegger P, Zeyer K, Emmenegger L, Petermann JL, Czerwinski J, Mosimann T, Kasper M, Mayer A (2008) Secondary effects of catalytic diesel particulate filters: conversion of PAHs versus formation of Nitro-PAHs. Environ Sci Technol 42(10):3773-3779. doi:10.1021/Es7026949

16. Heeb NV, Schmid P, Kohler M, Gujer E, Zennegg M, Wenger D, Wichser A, Ulrich A, Gfeller U, Honegger P, Zeyer K, Emmenegger L, Petermann JL, Czerwinski J, Mosimann T, Kasper M, Mayer A (2010) Impact of low- and high-oxidation diesel particulate filters on genotoxic exhaust constituents. Environ Sci Technol 44(3):10781084. doi:10.1021/Es9019222

17. Heeb NV, Zennegg M, Haag R, Wichser A, Schmid P, Seiler C, Ulrich A, Honegger P, Zeyer K, Emmenegger L, Bonsack P, Zimmerli Y, Czerwinski J, Kasper M, Mayer A (2013) PCDD/F 
formation in an iron/potassium-catalyzed diesel particle filter. Environ Sci Technol 47(12):6510-6517. doi:10.1021/es400760h

18. Shi XC, Keane MJ, Ong T, Li SQ, Bugarski AB (2010) Mutagenicity of diesel exhaust particles from an engine with differing exhaust after treatments. J Toxicol Environ Health A 73(19):1314-1324. doi:10. 1080/15287394.2010.485030

19. Wenger D, Gerecke AC, Heeb NV, Zennegg M, Kohler M, Naegeli H, Zenobi R (2008a) Secondary effects of catalytic diesel particulate filters: reduced aryl hydrocarbon receptor-mediated activity of the exhaust. Environ Sci Technol 42(8):2992-2998. doi:10.1021/ Es071827x

20. Wenger D, Gerecke AC, Heeb NV, Naegeli H, Zenobi R (2008b) Catalytic diesel particulate filters reduce the in vitro estrogenic activity of diesel exhaust. Anal Bioanal Chem 390(8):2021-2029. doi:10. 1007/s00216-008-1872-8

21. Steiner S, Comte P, Czerwinski J, Muller L, Heeb NV, Mayer A, Fink A, Rothen-Rutishauser B (2013) Reduction in (pro-)inflammatory responses of lung cells exposed in vitro to diesel exhaust treated with a non-catalyzed diesel particle filter. Atmos Environ 81:117-124

22. Blank F, Rothen-Rutishauser B, Gehr P (2007) Dendritic cells and macrophages form a transepithelial network against foreign particulate antigens. Am J Respir Cell Mol 36(6):669-677. doi:10.1165/ rcmb.2006-0234OC

23. Morin JP, Hasson V, Fall M, Papaioanou E, Preterre D, Gouriou F, Keravec V, Konstandopoulos A, Dionnet F (2008) Prevalidation of in vitro continuous flow exposure systems as alternatives to in vivo inhalation safety evaluation experimentations: outcome from MAAPHRI-PCRD5 research program. Exp Toxicol Pathol 60(2-3): 195-205. doi:10.1016/j.etp.2008.01.007

24. Muller L, Comte P, Czerwinski J, Kasper M, Mayer ACR, Gehr P, Burtscher H, Morin JP, Konstandopoulos A, Rothen-Rutishauser B (2010) New exposure system to evaluate the toxicity of (Scooter) exhaust emissions in lung cells in vitro. Environ Sci Technol 44(7): 2632-2638. doi:10.1021/Es903146g

25. Steiner S, Czerwinski J, Comte P, Popovicheva OB, Kireeva E, Muller L, Heeb N, Mayer A, Petri-Fink A, Rothen-Rutishauser B (2013) Comparison of the toxicity of diesel exhaust produced by bioand fossil diesel combustion in human lung cells in vitro. Atmos Environ 81:380-388

26. Steiner S, Heeb NV, Czerwinski J, Comte P, Mayer A, Petri-Fink A, Rothen-Rutishauser B (2014) Test-methods on the test-bench: a comparison of complete exhaust and exhaust particle extracts for genotoxicity/mutagenicity assessment. Environ Sci Technol. doi:10. 1021/es4056033

27. Steiner S, Mueller L, Popovicheva OB, Raemy DO, Czerwinski J, Comte P, Mayer A, Gehr P, Rothen-Rutishauser B, Clift MJD (2012) Cerium dioxide nanoparticles can interfere with the associated cellular mechanistic response to diesel exhaust exposure. Toxicol Lett 214(2):218-225. doi:10.1016/j.toxlet.2012.08.026

28. Muller L, Comte P, Czerwinski J, Kasper M, Mayer ACR, Schmid A, Rosinus L, Clift MJD, Steiner S, Gehr P, Rothen-Rutishauser B (2012) Investigating the potential for different scooter and car exhaust emissions to cause cytotoxic and (pro-)inflammatory responses to a $3 \mathrm{D}$ in vitro model of the human epithelial airway. Toxicol Environ Chem 94(1):164-180. doi:10.1080/02772248.2011.632509

29. Bunger J, Krahl J, Franke HU, Munack A, Hallier E (1998) Mutagenic and cytotoxic effects of exhaust particulate matter of biodiesel compared to fossil diesel fuel. Mutat Res Genet Toxicol Environ 415(1-2):13-23

30. Miller A, Ahlstrand G, Kittelson D, Zachariah M (2007) The fate of metal (Fe) during diesel combustion: morphology, chemistry, and formation pathways of nanoparticles. Combust Flame 149(1-2): 129-143. doi:10.1016/j.combustflame.2006.12.005

31. Donaldson K, Tran L, Jimenez LA, Duffin R, Newby DE, Mills N, MacNee W, Stone V (2005) Combustion-derived nanoparticles: a review of their toxicology following inhalation exposure. Part Fibre Toxicol 2:10. doi:10.1186/1743-8977-2-10

32. Zhang HY, Ji ZX, Xia T, Meng H, Low-Kam C, Liu R, Pokhrel S, Lin SJ, Wang X, Liao YP, Wang MY, Li LJ, Rallo R, Damoiseaux R, Telesca D, Madler L, Cohen Y, Zink JI, Nel AE (2012) Use of metal oxide nanoparticle band gap to develop a predictive paradigm for oxidative stress and acute pulmonary inflammation. ACS Nano 6(5): 4349-4368. doi:10.1021/Nn3010087

33. Podechard N, Lecureur V, Le Ferrec E, Guenon I, Sparfel L, Gilot D, Gordon JR, Lagente V, Fardel O (2008) Interleukin-8 induction by the environmental contaminant benzo(a)pyrene is aryl hydrocarbon receptor-dependent and leads to lung inflammation. Toxicol Lett 177(2):130-137. doi:10.1016/j.toxlet.2008.01.006

34. Umbuzeiro GA, Franco A, Martins MH, Kummrow F, Carvalho L, Schmeiser HH, Leykauf J, Stiborova M, Claxton LD (2008) Mutagenicity and DNA adduct formation of PAH, nitro-PAH, and oxy-PAH fractions of atmospheric particulate matter from Sao Paulo, Brazil. Mutat Res Genet Toxicol Environ 652(1):72-80. doi:10.1016/ j.mrgentox.2007.12.007

35. McGregor DB, Partensky C, Wilbourn J, Rice JM (1998) An IARC evaluation of polychlorinated dibenzo-p-dioxins and polychlorinated dibenzofurans as risk factors in human carcinogenesis. Environ Health Perspect 106:755-760. doi:10.2307/3433830

36. Ratcliff MA, Dane AJ, Williams A, Ireland J, Luecke J, McCormick RL, Voorhees KJ (2010) Diesel particle filter and fuel effects on heavy-duty diesel engine emissions. Environ Sci Technol 44(21): 8343-8349. doi:10.1021/es1008032

37. Lucking AJ, Lundback M, Barath SL, Mills NL, Sidhu MK, Langrish JP, Boon NA, Pourazar J, Badimon JJ, GerlofsNijland ME, Cassee FR, Boman C, Donaldson K, Sandstrom T, Newby DE, Blomberg A (2011) Particle traps prevent adverse vascular and prothrombotic effects of diesel engine exhaust inhalation in men. Circulation 123(16):1721-U1766. doi:10.1161/ Circulationaha.110.987263

38. Popovicheva OB, Kireeva E, Steiner S, Rothen-Rutishauser B, Persiantseva NM, Timofeev MA, Shonija NK, Comte P, Czerwinski J (2014) Microstructure and chemical composition of diesel and biodiesel particle exhaust. Aerosol Air Qual Res. doi:10. 4209/aaqr.2013.11.0336

39. Westphal GA, Krahl J, Munack A, Rusche Y, Schroder O, Hallier E, Bruning T, Bunger J (2012) Mutagenicity of diesel engine exhaust is eliminated in the gas phase by an oxidation catalyst but only slightly reduced in the particle phase. Environ Sci Technol 46(11):64176424. doi:10.1021/Es300399e

40. McDonald JD, Campen MJ, Harrod KS, Seagrave J, Seilkop SK, Mauderly JL (2011) Engine-operating load influences diesel exhaust composition and cardiopulmonary and immune responses. Environ Health Perspect 119(8):1136-1141. doi:10.1289/Ehp. 1003101 